\title{
Cartões telefônicos como fontes para a pesquisa histórica: possibilidades de pesquisa em Cultura Visual
}

Eduardo Cristiano Hass da SILVA ${ }^{1}$

Resumo:

O presente artigo tem por objetivo discutir a utilização de cartões telefônicos como fontes para a pesquisa em História. Dessa forma, o texto estrutura-se em três partes. Inicialmente, apresentam-se alguns apontamentos sobre Cultura Visual, campo teórico em que está discussão se insere. Em seguida, apresento alguns apontamentos sobre a utilização de cartões telefônicos na pesquisa histórica, exemplificando a partir da série Estações Férreas do Rio Grande do Sul. Para finalizar, aponto algumas possibilidades de estudo a partir dos cartões telefônicos, apresentando possíveis séries para análise.

Palavras-chave:

Fontes visuais. Pesquisa histórica. Cartões telefônicos.

\section{Phone cards as sources for historical research: possibilities for research in Visual Culture}

\begin{abstract}
:
This article aims to discuss the use of phone cards as sources for historical research. The text is structured into three parts. In the first one, I present some notes on Visual Culture, the theoretical field in which the work is inserted. Next, some notes are presented on the use of telephone cards in historical research, with the example of the series Estações Férreas do Rio Grande do Sul. To conclude, some possibilities of study are proposed from the phone cards, presenting possible series for analysis.
\end{abstract}

Keywords:

Visual fonts. Historical research. Phone cards.

\section{Tarjetas telefónicas como fuentes para la investigación histórica: posibilidades de investigación en Cultura Visual}

\begin{abstract}
Resumen:
Este artículo tiene por objetivo discutir la utilización de tarjetas telefónicas como fuentes para la investigación en Historia. El texto se estructura en tres partes. Inicialmente, se presentan algunos apuntes sobre Cultura Visual, campo teórico en que está discusión se inserta. A continuación, presento algunos apuntes sobre el uso de tarjetas telefónicas en la investigación histórica, ejemplificando a partir de la serie Estaciones Férreas de Rio Grande do Sul. Para finalizar, presento algunas posibilidades de estudio a partir de las tarjetas telefónicas, destacando posibles series para análisis.
\end{abstract}

Palabras clave:

Fuentes visuales. Investigación histórica. Tarjetas telefónicas.

\section{Introdução}

De acordo com o Museu Histórico Nacional (s.n.), Telecartofilia é o nome dado à arte de colecionar cartões de telefone, que podem ser reunidos e organizados sob distintos temas.

\footnotetext{
${ }^{1}$ Graduado e mestre em História pela Pontifícia Universidade Católica do Rio Grande do Sul (PUCRS), doutorando em Educação pela Universidade do Vale do Rio dos Sinos (UNISINOS), bolsista CNPq. E-mail: eduardohass.he@ gmail.com.
} 
Foi a partir do contato com esse conceito que pude nomear uma prática que alguns tiveram nos tempos de infância: colecionar cartões telefônicos. Agora, tomo esses cartões não apenas como parte de uma coleção salvaguardada em um acervo pessoal, mas como fontes visuais potentes para a pesquisa historiográfica.

O Museu Histórico Nacional (s.n.) destaca que o primeiro cartão telefônico surgiu na Itália, no ano de 1976. No caso brasileiro os testes se iniciaram em 1987, resultando na invenção do cartão indutivo, de autoria do engenheiro Nelson Guilherme Bardini, premiado em concurso da Telebrás em 1992. No mesmo ano em que a Telebrás realizou o Concurso de Inventores, surge o cartão comercial ${ }^{2}$ no país, substituindo as fichas metálicas utilizadas até então. Segundo Sibila Francine Tengaten Binotto (2005), ao longo dos anos 1990, os cartões foram gradativamente introduzidos na vida dos brasileiros, sendo que, ao mesmo tempo em que passavam a ocupar e circular no espaço urbano, surgiam os primeiros colecionadores e estudiosos do assunto.

Ao longo da história do uso e circulação desses cartões, eles foram empregados como veículo de propaganda por empresas particulares, instituições culturais e programas que estamparam e divulgaram imagens de seus interesses. Pesquisas de diferentes áreas têm se utilizado dos cartões telefônicos, seja como fonte ou como objeto de estudo. No âmbito da saúde, destaca-se o trabalho de Adriana Kelly Santos, Ana Paula Goulart Ribeiro e Simone Monteiro (2012). Ao analisarem a recepção de materiais educativos por portadores de hanseníase atendidos no município do Rio de Janeiro, as autoras identificaram que, além de cartilhas e cartazes de divulgação, algumas séries de cartões foram utilizadas como material educativo para conscientização sobre a doença.

Na pesquisa em Educação, o trabalho de Teresinha Silva de Oliveira (2003) discute como os estereótipos de índios(as) são instituídos a partir de diferentes olhares que se materializam em diversos artefatos, dentre eles, os cartões telefônicos. Na comunicação, Severino Alves de Lucena Filho (2009) analisa como o discurso organizacional de um evento turístico e cultural, "O Maior São João do Mundo”, realizado na cidade de Campina Grande, na Paraíba, é materializado em séries de cartões telefônicos.

No campo da linguística, Gabriela do Couto Baroni (2009) analisa a utilização de cartões telefônicos como suportes incidentais para gêneros textuais, ou seja, como suportes que não foram elaborados com a função de portarem textos escritos, mas que oferecem

\footnotetext{
${ }^{2}$ É importante ressaltar que, no Brasil, os primeiros cartões foram fabricados pela Casa da Moeda do Brasil e, em seguida, por empresas como a American Bank Note, Engephan, CPQD e Sercomtel. (MUSEU HISTÓRICO NACIONAL, s.n.).
} 
essa possibilidade. Na pesquisa histórica, Tamara Claudia Coimbra (2014) analisa cartões telefônicos para propor uma reflexão entre história local e imagens, tentando compreender como a cidade pode ser relida a partir de fatos e momentos oficializados como marca histórica e temporal de um dado lugar.

Neste estudo, proponho pensar o uso dos cartões telefônicos como fonte para pesquisa historiográfica, a partir da articulação entre texto e imagem presentes nesses suportes. A coleção de cartões telefônicos aqui apresentada é composta por um total de 954 peças, distribuídas em 16 porta cartões. Essa coleção foi constituída durante a minha infância e adolescência, ao longo dos anos 1990 e 2000, período no qual a prática de colecionar esses objetos fez parte de brincadeiras infantis ${ }^{3}$. Após realizar o curso de Licenciatura em História, observei que, além de salvaguardarem as lembranças dos tempos de escola, das reuniões de trocas e da prática de colecionar, a coleção de cartões poderia ser utilizada ainda como fonte para pesquisa historiográfica.

Sendo assim, inicio o texto apresentando alguns conceitos sobre Cultura Visual, campo teórico em que este estudo se insere, seguindo com algumas possibilidades de análise a partir dos cartões. Em seguida, apresento possíveis categorias para essa análise, ampliando as possibilidades de pesquisa para os historiadores. Para finalizar o trabalho, proponho algumas observações finais sobre a utilização dos cartões como fontes visuais.

\section{Estudos visuais e pesquisa histórica}

Ao refletir sobre a emergência dos estudos em Cultura Visual, Charles Monteiro (2013) afirma que a história ingressa nesse debate em um momento em que a discussão já está em pauta nos Estados Unidos da América (EUA), Grã-Bretanha, Canadá e Europa. No caso brasileiro, o tema já é debate em Programas de Pós-Graduação em Cultura Visual e Artes Visuais. Para Monteiro (2013), no caso específico da História, o trabalho na perspectiva da Cultura Visual exige um "educar o olhar", permitindo que o profissional seja capaz de apropriar-se de objetos, problemas, metodologias e categorias que o permitam pensar a dimensão visual da história:

A pesquisa histórica tem muito a ganhar ao entrar nesse debate sobre a interpretação da imagem e no âmbito dos estudos visuais ou de cultura visual, ao apropriar-se de objetos, de problemas, de metodologias e de categorias que permitam ao historiador pensar a dimensão visual da história, como prática social no tempo, bem como utilizar novas

\footnotetext{
${ }^{3}$ Segundo Binotto (2005), as crianças e os adolescentes estão entre os principais colecionadores de cartões telefônicos. Esse fenômeno justifica-se por diferentes motivos, como o caráter informativo/cultural do cartão; o uso de imagens no suporte e por esses cartões serem utilizados para um serviço específico após o qual são descartados, sendo relativamente fácil encontrá-los no meio urbano.
} 
tecnologias para o ensino da história e a divulgação de suas pesquisas. Formar cidadãos que possam interpretar um mundo que se oferece cada vez mais mediado por um imenso fluxo de imagens, também é tarefa dos historiadores (MONTEIRO, 2013, p. 14).

O trecho em destaque evidencia o alargamento das possibilidades de pesquisa em história, utilizando-se de fontes visuais, por meio da Cultura Visual. Para pensar essa dimensão visual, Monteiro (2013) destaca a importância que as imagens exercem sobre nós e que, para ele, acompanham o homem desde o processo de hominização, estando presentes em diferentes momentos da vida, exercendo diferentes funções (religiosa, educativa, informativa, etc.).

Para explicar as diferentes formas do "olhar as imagens", Monteiro (2013) retoma de Régis Debray ${ }^{4}$ a concepção das três midiasferas da relação do homem com as imagens: a logosfera (caracterizada como o período do olhar mágico, no qual a imagem representava o irrepresentável, situado na antiguidade); a grafosfera (situada entre os séculos XV e XVIII, que é a responsável por inaugurar a era da arte e do olhar estético); e a videosfera (surgida no século XX, a partir dos anos 1970, fruto, dentre outras coisas, da massificação da televisão em cores, do videocassete e dos computadores). Para o autor, a videosfera é o marco inicial da "Era do Visual".

Ao apresentar um panorama histórico acerca do surgimento dos Estudos Visuais, Monteiro (2013) destaca que, por volta de 1972, o campo da História da Arte preocupou-se com novos questionamentos sobre a interpretação da imagem, em uma articulação da Arte com a História Social. Em 1980, nos Estados Unidos, as pesquisas organizaram-se ao redor de um novo campo de pesquisas interdisciplinares, os Estudos Visuais, articulando um campo interdisciplinar, com diferentes profissionais.

Outro autor que apresenta o potencial interdisciplinar dos Estudos Visuais é Fischman (2004). Ao falar de como o campo da pesquisa educacional norte-americana viu emergir, entre as décadas de 1990-2000, os vários trabalhos sobre Cultura Visual, destaca que dentre os temas pesquisados encontravam-se televisão, fotografia, artes, desenhos e imagens. Dessa forma, acredito que os cartões telefônicos podem ser pensados como mais uma fonte visual, analisada a partir do referencial da Cultura Visual. Defendo ao longo deste texto que os cartões são fontes potentes para a pesquisa histórica, mas ainda pouco exploradas.

\footnotetext{
${ }^{4}$ DEBRAY, Regis. Vida e morte da imagem. Uma história do olhar no ocidente. Petrópolis: Vozes, 1993.
} 


\section{Cartões telefônicos como fontes potentes na pesquisa historiográfica}

Segundo Maria Eliza Linhares Borges (2003, p. 37), "ao longo dos séculos, as diferentes sociedades têm criado distintas formas de produzir, olhar, conceber, dialogar e utilizar suas produções imagéticas". Ao falar do uso de imagens na contemporaneidade, Fischman (2004, p. 14) destaca que é inegável que com a expansão do capitalismo intensificou-se a circulação das imagens: "as imagens se tornam onipresentes e meios esmagadores de difundir signos, símbolos e informação". É nesse contexto de intensificação da circulação e popularização das imagens que os cartões telefônicos devem ser pensados. Utilizando-me da citação de Fischman (2004), penso que os cartões funcionaram como suporte para a divulgação de signos, símbolos e informações.

Considerando os cartões telefônicos como fontes historiográficas, destaco que os mesmos são compostos de elementos escritos e visuais. Assim, embora a centralidade deste trabalho esteja na visualidade, é importante destacar que entendo os cartões a partir da articulação entre "pena e pincel" apresentação prévia da tipologia da fonte em estudo.

Imagem 1 - Cartão telefônico série Estações Férreas do Rio Grande do Sul (Frente)

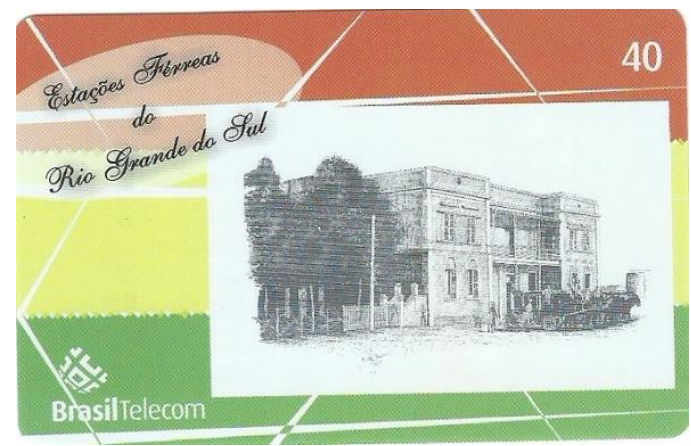

Fonte: Acervo pessoal do autor.

\footnotetext{
${ }^{5}$ A ideia de articulação entre pena e pincel é concebida a partir da historiadora Maria Eliza Linhares Borges (2001). Ao analisar a obra Viagem Pitoresca ao Brasil, de J. B. Debret, a pesquisadora discute as nuances da articulação entre texto (pena) e imagem (pincel), que revelam uma concepção de Nação Brasileira.
} 
Imagem 2 - Cartão telefônico série Estações Férreas do Rio Grande do Sul (Verso)

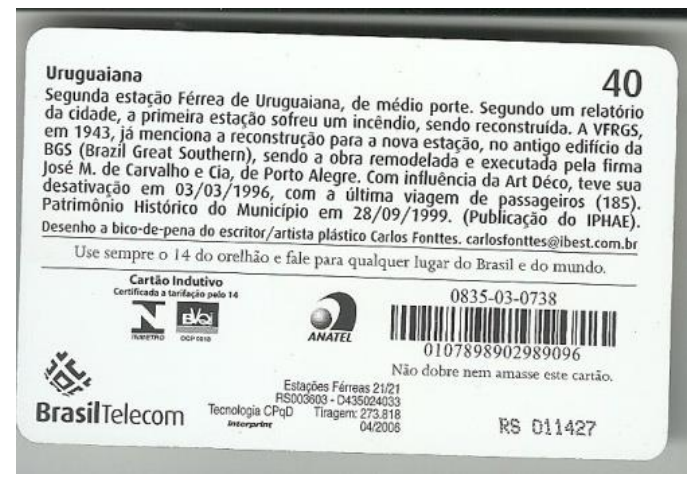

Fonte: Acervo pessoal do autor.

As imagens 1 e 2 referem-se à frente e verso de um cartão telefônico, cuja medida é de $8 \times 5 \mathrm{~cm}$. Como podemos observar, a frente do cartão aglutina elementos escritos e visuais. O fundo da imagem do cartão está dividido em três linhas horizontais, cujas cores são vermelho, amarelo e verde. As três cores que compõem o fundo são as mesmas cores da bandeira do estado do Rio Grande do Sul, que também traz três linhas. Embora remeta à bandeira do Rio Grande do Sul, é importante destacar que o fundo do cartão não é uma transposição direta. Enquanto na bandeira as linhas estão em diagonal, sendo a ordem das cores verde, vermelho e amarelo, no cartão, as linhas estão na horizontal, sendo a ordem das cores vermelha, amarela e verde.

No canto superior esquerdo do cartão pode-se observar uma esfera com destaque em relação ao fundo, contendo o texto "Estações Férreas do Rio Grande do Sul". Considerando esse texto, as cores e linhas do fundo do cartão justificam-se em sua relação com a bandeira desse estado. No canto inferior esquerdo observa-se o texto "BrasilTelecom", que corresponde ao nome da empresa de telefonia. Além disso, no canto superior direito do cartão consta o número “40”, que remete às unidades (medida utilizada para medir o tempo de ligação) do cartão.

Ocupando a maior parte da área que compõe a frente do cartão encontra-se uma imagem, situada ao centro, com deslocamento para a direita inferior do cartão. A imagem em preto e branco mostra um prédio histórico, composto por dois andares, janelas e portas frontais e árvores à esquerda. Além disso, pode-se observar que em frente ao prédio encontram-se carroças ou charretes, puxadas por animais. Próximo a essas charretes podemos observar figuras humanas que se deslocam. Alguns questionamentos emergem da 
observação dessa imagem. Que prédio é esse? De que período é sua construção? Ainda existe? Onde está situado? Quem seriam as pessoas que o rodeiam?

É na articulação entre a pena e o pincel que se encontram as respostas a esses questionamentos. Embora a frente do cartão não traga mais informações sobre a imagem, o texto existente no verso pode responder alguns dos questionamentos:

Segunda estação Férrea de Uruguaiana, de médio porte. Segundo um relatório da cidade, a primeira estação sofreu um incêndio, sendo reconstruída. A VFRGS, em 1943, já menciona a reconstrução para a nova estação, no antigo edifício da BGS (Brazil Greath Southern), sendo a obra remodelada e executada pela firma José M. de Carvalho e Cia., de Porto Alegre. Com influência da Art Déco, teve sua desativação em 03/03/1996, com a última viagem de passageiros (185). Patrimônio Histórico do Município em 28/09/1999. (Publicação do IPHAE). (CARTÃO ESTAÇÕES FÉRREAS, 2006, verso).

Como se pode observar no texto, a fotografia presente na frente do cartão refere-se a uma estação férrea da cidade de Uruguaiana, Rio Grande do Sul. Além disso, o texto evidencia que a estação é construída no local da primeira (que sofreu um incêndio), sendo responsável pela sua construção a empresa José M. de Carvalho e Cia, cuja sede encontrava-se em Porto Alegre. O texto menciona também que a estação funcionou até o ano de 1996, quando sediou sua última passagem de passageiros, tendo sido declarada patrimônio histórico do município em 1999.

Acredito que esse primeiro contato com os cartões telefônicos já mostre parte do seu potencial para a pesquisa histórica. Considerando esse suporte como uma fonte visual (articulando texto e imagem), é importante analisá-lo a partir dos pressupostos teóricos da Cultura Visual. De acordo com Peter Burke (2004), o significado das imagens depende do seu contexto social, entendido por ele como contexto geral (em âmbito cultural, político, entre outros), bem como do lugar de onde se pretende exibi-las.

Visando a analisar o contexto social dessa imagem, começa a busca por elementos como a data de sua produção e circulação. Tomando o cartão analisado como exemplo, observa-se que existe uma sobreposição de datas em relação a ele. Inicialmente, tem-se a data de construção do prédio destacado que, de acordo com o verso do cartão, data da década de 1940. No entanto, a análise atenta desse suporte revela pelo menos mais duas temporalidades. Ainda no verso, encontra-se a frase "Desenho e bico-de-pena do escritor/artista Carlos Fontes" (CARTÃO ESTAÇÕES FÉRREAS, 2006, verso). Mesmo não trazendo a data em que o artista desenhou a imagem em destaque, o historiador pode 
levantar a possibilidade de ela não ser a mesma da construção do prédio. Assim, temos a segunda temporalidade que envolve o cartão.

Atentando mais um pouco para o verso do cartão, na parte inferior, encontra-se outra data: 04/2006. Essa data refere-se à produção do cartão telefônico. Um questionamento pertinente para o estudo refere-se a qual das datas utilizar. Penso que o historiador tem o dever de destacar essa sobreposição temporal, no entanto, a temporalidade escolhida vai depender da pergunta e do objeto de análise. Se o historiador estiver realizando um estudo relacionado ao processo de urbanização da cidade de Uruguaiana, por exemplo, a data de construção da estação é central no seu trabalho. Porém, se o historiador estiver pesquisando as obras de Carlos Fontes, a data de realização do desenho será central. Uma terceira possibilidade refere-se ao estudo do próprio cartão como objeto de pesquisa. Se o historiador estiver centrado na produção e circulação dos cartões ou nas representações por eles veiculadas, a data de emissão será a central na sua pesquisa.

Como tenho argumentado desde o início, este texto tem o objetivo de mostrar o potencial dos cartões telefônicos como fontes visuais para a pesquisa histórica. Dessa maneira, retomo quatro apontamentos de Burke (2004) sobre a pesquisa com imagens. A primeira afirmação do autor que retomo diz que "as imagens dão acesso não ao mundo social diretamente, mas sim a visões contemporâneas daquele mundo" (BURKE, 2004, p. 236). Assim como a pesquisa com qualquer outra fonte visual, a pesquisa com os cartões deve levar em conta esse pressuposto, uma vez que eles veiculam representações de uma determinada sociedade.

O segundo ponto destacado por Burke (2004) é de que os testemunhos das imagens devem ser colocados dentro dos seus contextos. Essas duas concepções do autor são reforçadas por Fischman (2004, p. 115) ao afirmar que “[...] para se entender a visualidade é preciso investigar tanto a percepção e a recepção de imagens, quanto as condições culturais, sociais e econômicas que envolvem os produtores e os usuários da cultura visual”. Com o cartão anteriormente analisado, observou-se a existência de pelo menos três temporalidades, três contextos, cuja problemática do pesquisador é quem dirá qual o contexto a ser aprofundado.

O terceiro e quarto ponto abordado pelo autor afirma que uma série de imagens oferece um testemunho mais confiável do que uma imagem isolada, e que o historiador 
precisa ler nas entrelinhas dessas imagens. Proponho pensar essas duas observações a partir do cartão anteriormente analisado.

Tomando novamente o cartão telefônico que traz a estação férrea de Uruguaiana e considerando a importância de entender uma imagem dentro de uma série, pode-se questionar: esse cartão foi o único produzido com essa temática? Existiram outros? $\mathrm{O}$ verso do cartão apresenta os dizeres "Estações Férreas 21/21", o que leva a inferir que esse cartão seja o número 21 de uma série de 21 cartões. Embora o arquivo não contenha todos os cartões da série, 11 deles foram localizados, como é possível observar nas imagens que seguem:

Imagem 3 - Série Estações Férreas do Rio Grande do Sul (parte 1)

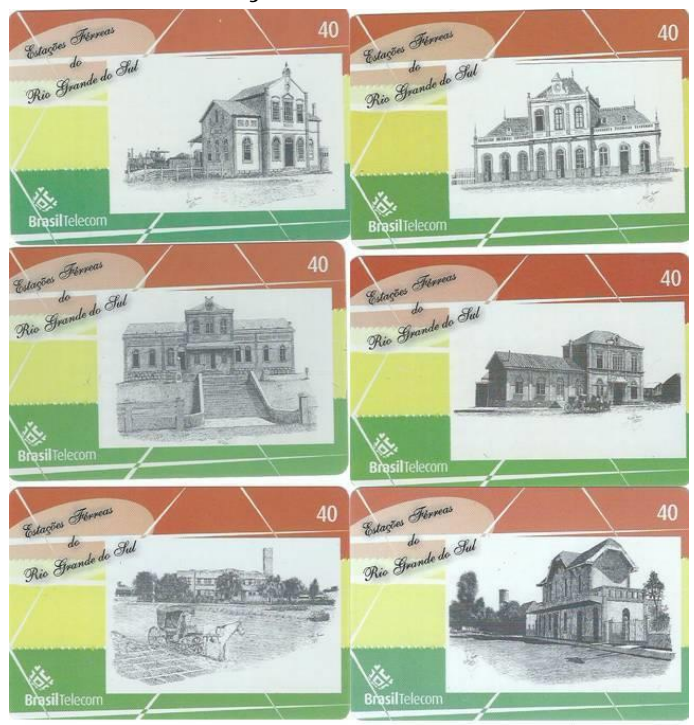

Fonte: Acervo pessoal do autor.

Imagem 4 - Série Estações Férreas do Rio Grande do Sul (parte 2)

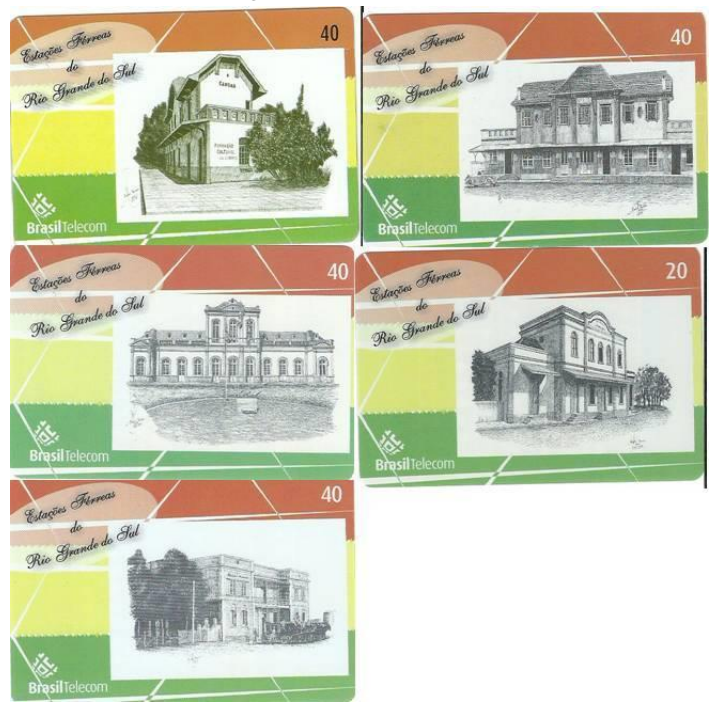

Fonte: Acervo pessoal do autor. 
Ao observar as imagens 3 e 4 percebe-se que o cartão Estação Férrea de Uruguaiana está inserido em uma série de imagens, cujo nome é "Estações Férreas do Rio Grande do Sul". Analisando as imagens em conjunto, pode-se inferir que alguns dos elementos presentes no cartão analisado fazem parte da série: fundo dividido em três faixas horizontais, em que as cores lembram a bandeira do Rio Grande do Sul; articulação entre texto e imagem; disposição dos desenhos das estações, entre outros.

Burke (2004) salienta que qualquer um que quiser recorrer às imagens como evidência necessita estar consciente de que elas, em sua maioria, não foram produzidas para esse propósito, sendo que historiadores de diferentes temas e áreas podem utilizá-las. Dessa forma, é importante destacar que os cartões telefônicos não foram produzidos com o intuito de servirem de fonte para o historiador. Podemos inferir que foram comercializados de forma separada, fragmentada, sem a preocupação em manter a série unida. Nesse momento, o trabalho de coleta do historiador aproxima-se do trabalho do colecionador, tendo que pesquisar, procurar, vasculhar diferentes lugares que possam salvaguardas esses suportes. Em seguida, o trabalho prossegue com a reunião da série, que será organizada, catalogada e analisada. Enquanto eram vendidos em unidades, os cartões encontravam-se fragmentados, individualizados, separados. Reunidos no álbum do historiador e/ou colecionador, constituem um coletivo, uma série, uma narrativa. No caso da série analisada, encontra-se salvaguardada no acervo do autor, conforme a seguinte disposição:

Quadro 1 - Coleção de cartões telefônicos.

\begin{tabular}{|l|l|l|}
\hline $\begin{array}{l}\text { Porta } \\
\text { cartões }\end{array}$ & Série & $\begin{array}{l}\text { Quanti } \\
\text { dade }\end{array}$ \\
\hline $\begin{array}{l}\text { Porta } \\
\text { cartões 1 }\end{array}$ & $\begin{array}{l}\text { Série Cães de Luxo e Companhia, Brasil Telecom, } \\
\text { Preserve a Fauna e os Orelhões do Brasil, Recarga Tim e } \\
\text { Recarga Claro. }\end{array}$ & 56 \\
\hline $\begin{array}{l}\text { Porta } \\
\text { cartões 2 }\end{array}$ & Recarga Vivo, Belezas do Mar, Série Personalidades. \\
cartões 3 & $\begin{array}{l}\text { Frutas, Arquitetura de Porto Alegre, Cidades Gaúchas, } \\
\text { Tradições, } \\
\text { São João, Lembrança do Rio Grande do Sul, Vale dos Sinos, } \\
\text { Mídia Ibest. }\end{array}$ & 56 \\
\hline
\end{tabular}




\begin{tabular}{|c|c|c|}
\hline $\begin{array}{l}\text { Porta } \\
\text { cartões } 4\end{array}$ & $\begin{array}{l}\text { Série Unificado, Série Imagens de Torres, Série Museus, } \\
\text { Comidas Salgadas, Comidas Típicas do Arraial, Telefônica, } \\
\text { Tecnologia, Festas. }\end{array}$ & 56 \\
\hline $\begin{array}{l}\text { Porta } \\
\text { cartões } 5\end{array}$ & $\begin{array}{l}\text { Série Pizza Hut, Ligue-Ligue 14, Série Verão, Grêmio, Feliz } \\
2014, \\
\text { Série Dia das Mães, Vida Urgente, Série Independência do } \\
\text { Brasil. }\end{array}$ & 56 \\
\hline $\begin{array}{l}\text { Porta } \\
\text { cartões } 6\end{array}$ & $\begin{array}{l}\text { Porto Alegre, Calendário, Prédios de Porto Alegre, Tecnologia } \\
\text { Telebrás, Série Esportes e Calorias, Sítio do Pica-pau Amarelo, } \\
\text { Panorama do Cinema Gaúcho. }\end{array}$ & 56 \\
\hline $\begin{array}{l}\text { Porta } \\
\text { cartões } 7\end{array}$ & $\begin{array}{l}\text { BrasilTeleom, Cartão Cidadão, Ironman 2005, } \\
500 \text { Anos do Descobrimento, Porto Alegre, Copa 2006, } \\
\text { Significado dos Nomes, Pampas Safari. }\end{array}$ & 56 \\
\hline $\begin{array}{l}\text { Porta } \\
\text { cartões } 8\end{array}$ & $\begin{array}{l}\text { Brinquedos Infantis, Série Minis, Dia das Crianças, } 101 \\
\text { Dálmatas, } \\
\text { Meninos de Rua, Itapua, Série Aventura, Patagônia, } \\
\text { Quadrões Turma da Mônica, Série Dinossauros. }\end{array}$ & 56 \\
\hline $\begin{array}{l}\text { Porta } \\
\text { cartões } 9\end{array}$ & $\begin{array}{l}8 \text { Jeitos de Mudar o Mundo, Bases Aéreas, Salva Vidas, Papai } \\
\text { Noel. }\end{array}$ & 42 \\
\hline $\begin{array}{l}\text { Porta } \\
\text { cartões } 10\end{array}$ & Bases Aéreas, Folia, Férias, Festas, Anti Fraude. & 42 \\
\hline $\begin{array}{l}\text { Porta } \\
\text { cartões } 11\end{array}$ & $\begin{array}{l}\text { Feliz 2006, Planetas, Série Praias e Lagoas, } \\
\text { Imigrantes do Rio Grande do Sul, Retratos de Minas, Férias } \\
2005 .\end{array}$ & 42 \\
\hline $\begin{array}{l}\text { Porta } \\
\text { cartões } 12\end{array}$ & Jogo (Serie Superbola), Arte, Natal, Páscoa, Corredor Arte. & 42 \\
\hline $\begin{array}{l}\text { Porta } \\
\text { cartões } 13\end{array}$ & $\begin{array}{l}\text { Fases da Lua, Grande Florianópolis, Calendário 2002, Mapa, } \\
\text { Declaração dos Direitos da Criança, } \\
\text { Estações Férreas do Rio Grande do Sul. }\end{array}$ & 42 \\
\hline
\end{tabular}




\begin{tabular}{|c|c|c|}
\hline $\begin{array}{l}\text { Porta } \\
\text { cartões } 14\end{array}$ & $\begin{array}{l}\text { Amigo, Telefônica, Natal, Telefones Antigos, Ministério da } \\
\text { Saúde - Hepatite, Meninas Super Poderosas, Dia dos } \\
\text { Namorados, } \\
\text { Atletas de Ouro, Carnaval, A Casa das Sete Mulheres, Dia das } \\
\text { Mães, } \\
\text { Dia dos Pais, Série Raddicci, Festas da Uva, Segredos da } \\
\text { Páscoa, } \\
\text { Exercícios, As Belezas de Uruguaiana. }\end{array}$ & 126 \\
\hline $\begin{array}{l}\text { Porta } \\
\text { cartões } 15\end{array}$ & $\begin{array}{l}\text { Signos, Série Locomotivas, Papas, Obras de Arte, Museus, } \\
\text { Estâncias de Bagé, Olimpíadas, Festas, Locais de Santa } \\
\text { Catarina, Orquídeas, Centros Históricos, Pintores Brasileiros, } \\
\text { Independência do Brasil, Hanseníase. }\end{array}$ & 126 \\
\hline $\begin{array}{l}\text { Porta } \\
\text { cartões } 16\end{array}$ & $\begin{array}{l}\text { Copa do Mundo Coreia/Japão 2002, Gato Persa, Feliz Ano } \\
\text { Novo, } \\
\text { Nossos Direitos. }\end{array}$ & 44 \\
\hline Total: & & 954 \\
\hline
\end{tabular}

Fonte: Elaborado pelo autor.

\section{Possibilidades de pesquisa: séries para análise}

Movimentando-me em direção à finalização deste trabalho, proponho enumerar alguns campos passíveis de análise pelo historiador a partir das séries apresentadas no Quadro 1. Intitulo o primeiro campo a ser estudado como Objetos da Natureza, tema que, de acordo com Lima e Carvalho (2015), está presente na produção e circulação das imagens desde as origens da fotografia, já que, em 1839, ao difundir-se entre as ciências, foi utilizada em estudos do espectro solar. O campo Objetos da Natureza pode ser composto pelas séries Belezas do Mar (Porta cartões 2), Frutas (Porta cartões 3), Pampas Safari (Porta cartões 7), Itapuã, Série Aventura, Patagônia (Porta cartões 8), Planetas, Série Praias e Lagoas (Porta cartões 11) e Fases da Lua, (Porta cartões 13).

O segundo campo que emerge a partir da análise das séries dispostas no quadro é Arquitetura e Cidades. Assim como Objetos da Natureza, esse é um tema com significativo espaço para discussão a partir das imagens. Como observaram Lima e Carvalho (2015, p. 33), “assim como ocorreu com o retrato, os álbuns fotográficos toram os primeiros difusores da imagem de cidade do século XIX”. Além disso, os cartões telefônicos com 
imagens de diferentes cidades, retratando locais históricos e pontos turísticos podem ser pensados na lógica dos cartões-postais, que como já mostrou Borges (2003), traziam imagens do que era considerado o ideal de belo: prédios públicos, construções arquitetônicas, entre outros, podendo ser utilizados para o estudo do espaço público . O campo Arquitetura e Cidades pode ser formado pelas séries Arquitetura de Porto Alegre, Cidades Gaúchas (Porta cartões 3), Porto Alegre, Prédios de Porto Alegre, (Porta cartões 6), Porto Alegre (Porta cartões 7), Bases Aéreas (Porta cartões 9), Retratos de Minas (Porta cartões 11), Estações Férreas (Porta cartões 13), As Belezas de Uruguaiana (Porta cartões 14) e Centros Históricos e Locais de Santa Catarina (Porta cartões 15) .

O próximo campo pode ser chamado de Festas, Rituais e Cultura Popular, sendo formado por uma ampla variedade de séries: Tradições, Festa de São João (Porta cartões 3), Comidas Salgadas, Comidas Típicas do Arraial (Porta Cartões cartões 4), Feliz 2014, Série Dia das Mães (Porta cartões 5), Panorama do Cinema Gaúcho (Porta cartões 6), Significado dos Nomes (Porta cartões 7), Papai Noel (Porta cartões 9), Festas (Porta cartões 10), Feliz 2006 (Porta cartões 11), Arte, Natal, Páscoa (Porta cartões 12), Natal (Porta cartões 14) e Signos (Porta cartões 15). A circulação de imagens referentes à cultura popular é estudada por Borges (2003) ao analisar fotografias e representações da morte no nordeste brasileiro, com atenção especial à imagem de Lampião e seu grupo morto. Ao analisar o papel social da fotografia, Monteiro (2013) destaca que ela pode ser vista como uma forma de popularização da imagem. Penso que assim como as fotografias, as imagens que circularam a partir dos cartões telefônicos também contribuíram para o processo de popularização iconográfica, uma vez que o suporte fez parte do cotidiano daqueles que desejavam utilizar os telefones públicos.

O quarto campo possível é particularmente interessante para o trabalho do historiador. Intitulado Temas Históricos, é composto pelas séries Independência do Brasil (Porta cartões 5), 500 Anos do Descobrimento (Porta cartões 7), Imigrantes do Rio Grande do Sul (Porta cartões 11), Estações Férreas do Rio Grande do Sul (Porta cartões 13), Telefones Antigos (Porta cartões 14), A Casa das Sete Mulheres (Porta cartões 14), Papas, Obras de Arte, Museus, Estâncias de Bagé, Pintores Brasileiros e Independência do Brasil (Porta cartões 15). Esse campo merece algumas observações específicas. Inicialmente, destacando a presença de algumas datas historicamente importantes para a história brasileira, como a Independência do Brasil (título dado a duas séries diferentes) e 500 anos do Descobrimento. Só essas séries já permitiriam um trabalho histórico de fôlego. 
Ainda nesse campo, destaco a série Estações Férreas do Rio Grande do Sul, que, como anteriormente analisada, pode ser usada para pensar também elementos específicos sobre Arquitetura e Cidades, mostrando como essas categorias podem ser feitas e refeitas a partir dos questionamentos do historiador. Outra série que destaco dentro desse campo é a intitulada A Casa das Sete Mulheres (Porta cartões 14). Essa série tem o título de uma minissérie apresentada por um canal aberto da televisão brasileira, cujo tema central foi a Guerra dos Farrapos (1835-1845). Destaco-a para mostrar a possibilidade de articulação dos cartões telefônicos a outras fontes, principalmente às audiovisuais. Ao analisar as fontes audiovisuais, Napolitano (2015) atenta especificamente para cinema, vídeo independente, televisão e música.

Considerando que A Casa das Sete Mulheres foi uma minissérie de televisão exibida em rede nacional e, mesmo com todos os preconceitos que ainda se observam em torno do trabalho historiográfico com fontes televisivas (NAPOLITANO, 2015), a minissérie em evidência pode tornar-se objeto de estudo do historiador. Uma das fontes para essa investigação pode ser os cartões telefônicos, que permitem refletir sobre os públicos que a programação atingia, sua circulação e recepção. Dessa forma, os cartões telefônicos podem ser tomados para construir parte da narrativa histórica, mostrando que, para além da tela da televisão, os personagens da teledramaturgia estavam presentes também nos telefones públicos. Para exemplificar, seguem os cartões encontrados dessa série.

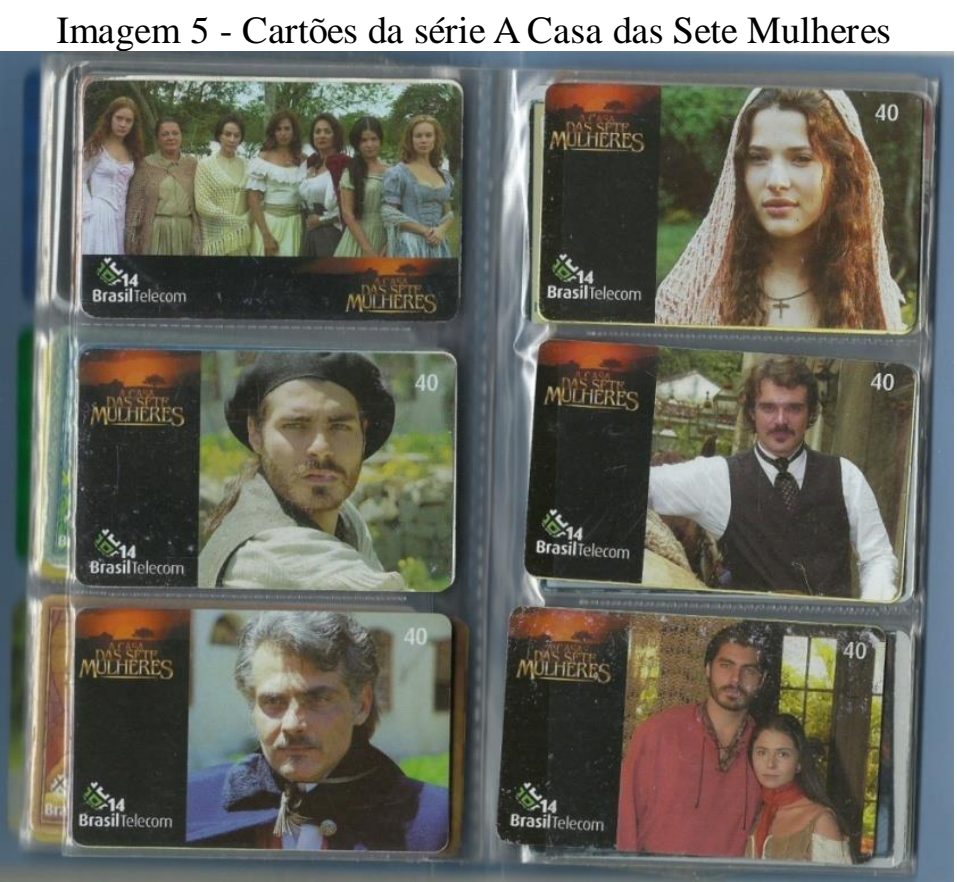

Fonte: Acervo pessoal do autor. 
Como podemos observar, com exceção do primeiro cartão, todos os outros da série trazem no lado esquerdo o nome da minissérie A Casa das Sete Mulheres e, do lado direito, a imagem individual, em dupla ou coletiva dos personagens. No caso do primeiro cartão, por exemplo, podem-se identificar as sete personagens mulheres que deram nome a série.

O quinto campo, chamado História da Educação e da Infância é composto pelas séries Sítio do Pica-pau Amarelo (Porta cartões 6), Brinquedos Infantis, Série Minis, Dia das Crianças, 101 Dálmatas, Meninos de Rua, Quadrões Turma da Mônica (Porta cartões 8), Declaração dos Direitos da Criança (Porta cartões 13) e Meninas Super Poderosas (Porta cartões 14). Esses cartões revelam elementos importantes acerca da cultura escolar e da cultura infantil, como brinquedos, representações e direitos das crianças, filmes e personagens destinados a crianças, entre outros. Além de estudos históricos, essas séries podem ser utilizadas também em pesquisas do campo da educação, como os propostos por Schwengber (2014), que analisa especificamente os discursos e imagens vinculados à revista Pais \& Filhos.

Para finalizar, apresento mais dois campos que podem ser estudados a partir dos cartões: Museus, formada pelas séries Museus (Porta cartões 4) e Telefones Antigos (Porta cartões 14) e o campo Esportes, formada pelas séries Grêmio Futebol Porto Alegre (Porta cartões 5), Esportes e Calorias, (Porta cartões 6), Jogo (Porta cartões 12), Atletas de Ouro, Exercícios (Porta cartões 14), Olimpíadas (Porta cartões 15) e Copa do Mundo Coreia/Japão 2002 (Porta cartões 16).

\section{Apontamentos}

Iniciei este texto evidenciando que tinha como objetivo mostrar as possibilidades de pesquisa historiográfica a partir da utilização de cartões telefônicos como fontes históricas. Para atender esse objetivo, apresentei os Estudos Visuais como o campo teórico onde esta proposta se insere e, em seguida, realizei um exercício de leitura crítica dessa fonte, procurando articular "pena e pincel” (BORGES, 2001) na construção do conhecimento histórico. Acredito que o exercício realizado a partir da Série Estações Férreas do Rio Grande do Sul mostra o potencial dos cartões telefônicos como fontes e até mesmo como objeto de pesquisa histórica. Esses suportes permitem compreender imagens, textos e discursos que foram produzidos e circularam em uma determinada época. Além disso, a possibilidade de análise em série pode mostrar similitudes e discrepâncias das ideias que circularam, bem como mudanças e permanências na produção e circulação desses artefatos. 
Defendo, assim, que historiadores, bem como outros pesquisadores, podem e devem incorporar tais suportes como fontes em suas pesquisas. Para corroborar com essa ideia, apresento possíveis campos de análise que emergem a partir da coleção estudada: Objetos da Natureza; Arquitetura e Cidades; Festas, Rituais e Cultura Popular; Temas Históricos; História da Educação e da Infância; Museus e Esportes. Esses campos não são fixos e podem mudar de acordo com o olhar do historiador. No entanto, atentar sobre eles revela diferentes temas que já são discutidos pelos historiadores e que podem agora ser ampliados a partir do uso desses suportes. Além disso, os diferentes campos mostram a possibilidade de continuidade deste estudo, uma vez que todos podem ser analisados.

Destaco que não foi intenção deste artigo esgotar o tema do uso dos cartões telefônicos na pesquisa histórica, pelo contrário, foi estimular historiadores e pesquisadores da Cultura Visual no sentido de utilizarem esse material como fonte. Novas pesquisas e problemáticas podem surgir desta proposta: como pensar os cartões telefônicos como suportes de memória? Seria possível uma história da circulação dos cartões? Quem são os colecionadores e quais os acervos pessoais destes suportes? Esses são questionamentos que possibilitam pesquisas futuras.

\section{Referências}

BARONI, Gabriela do Couto. O cartão telefônico como suporte para gêneros textuais. Cadernos do CNLF, Rio de Janeiro, v. 13, n. 4, p. 2204-2216, 2009 [Anais do XIII CNLF]. Disponível em: http://www.filologia.org.br/xiiicnlf/XIII_CNLF_04/tomo_2/o_cartao_telefonico_como_su porte_para_generos_GABRIELA.pdf. Acesso em: 16 jun. 2019.

BINOTTO, Sibila Francine Tengaten. Cidadania em fragmentos: um estudo sobre cartões telefônicos brasileiros. 2005. Monografia (Graduação em Biblioteconomia) - Faculdade de Biblioteconomia e Comunicação, Universidade Federal do Rio Grande do Sul, Porto Alegre, 2005.

BORGES, Maria Eliza Linhares. Imagens da nação brasileira. Locus, v.7, n. 1, p. 9-25, 2001. Disponível em: https://periodicos.ufjf.br/index.php/locus/article/view/20526. Acesso em: 16 jun. 2019.

BORGES, Maria Eliza Linhares. Tradição e modernidade na mira dos fotógrafos. In: História \& fotografia. Belo Horizonte: Autêntica, 2003. p. 37-73.

BURKE, Peter. A história cultural das imagens. In: Testemunha ocular: história e imagem. Bauru, SP: EDUSC, 2004. p. 225-238.

CARTÃO ESTAÇÕES FÉRREAS. BrasiTelecom. 2006. Acervo pessoal do autor. 
CHARTIER, Roger. À beira da falésia: a história entre incertezas e inquietudes. Porto Alegre: Editora Universidade/UFRGS, 2002.

COIMBRA, Tamara Claudia. Cidade e imagens: lugares vividos e praticados - o centenário da cidade de Ituiutaba. In: CONGRESSO INTERNACIONAL DE HISTÓRIA: cultura, sociedade e poder. 4., 2014, Jataí. Anais [...] Jataí: Universidade Federal de Goiás/Campus Jataí, 2014. p. 1-18. Disponível em: http://www.congressohistoriajatai.org/anais2014/Link\%20(258).pdf. Acesso em: 13 nov. 2017.

FISCHMAN, Gustavo E. Reflexões sobre imagens, cultura visual e pesquisa educacional. In: CIAVATTA, Maria; ALVES, Nilda (org.). A leitura de imagens na pesquisa social: história, comunicação e educação. São Paulo: Cortez, 2004. p. 109-125.

LIMA, Solange Ferraz de; CARVALHO, Vânia Carneiro de. Fotografias: usos sociais e historiográficos. In: PINSKY, Carla Bassanezi; LUCA, Tania Regina de. (org.). O historiador e suas fontes. São Paulo: Contexto, 2015. p. 29-49.

LUCENA FILHO, Severino Alves de. O Maior São João do Mundo em Campina Grande PB: um evento gerador de discursos culturais. Culturas Midiáticas, [João Pessoa], v. 2, n. 1, sem paginação, jan./jun. 2009. Disponível em: http://www.periodicos.ufpb.br/ojs2/index.php/cm/article/view/11695/6721. Acesso em: 13 nov. 2017.

MONTEIRO, Charles. Pensando sobre História, imagem e cultura visual. Patrimônio e Memória, São Paulo, v.9, n.2, p. 3-16, jul./dez., 2013. Disponível em: http://repositorio.pucrs.br/dspace/bitstream/10923/8294/2/Pensando_sobre_Imagem_Histor ia_e_Cultura_Visual.pdf. Acesso em: 15 nov. 2017.

MUSEU HISTÓRICO NACIONAL. Coleção de Cartões Telefônicos. In: http://mhn.museus.gov.br/. Acesso em: 15 nov. 2017.

NAPOLITANO, Marcos. Fontes audiovisuais: a História depois do papel. In: PINSKY, Carla Basselar. Fontes Históricas. 3. ed. São Paulo: Contexto, 2015. p. 235-289.

OLIVEIRA, Teresinha Silva de. Olhares que fazem a "diferença": o índio em livros didáticos e outros artefatos culturais. Rev. Bras. Educ. [on-line], Rio de Janeiro, n.22, p. 25-34, jan./abr. 2003. Disponível em: http://www.scielo.br/pdf/rbedu/n22/n22a04.pdf. Acesso em: 15 nov. 2017.

PESAVENTO, Sandra Jatahy. Com os olhos no passado: a cidade como palimpsesto. Revista esboços, Florianópolis, v. 11, n. 11, p. 25-30, [jan./jun.], 2004. Disponível em: https://periodicos.ufsc.br/index.php/esbocos/article/view/334/9893. Acesso em: 14 nov. 2017.

POSSAMAI, Zita Rosane. Fotografia, história e vistas urbanas. História, Franca, São Paulo, v. 27, n. 2, p. 253-277, 2008. Disponível em: http://www.scielo.br/pdf/his/v27n2/a12v27n2.pdf. Acesso em: 14 nov. 2017. 
SANTOS, Adriana Kelly; RIBEIRO, Ana Paula Goulart; MONTEIRO, Simone. Hanseníase e práticas da comunicação: estudo de recepção de materiais educativos em um serviço de saúde no Rio de Janeiro. Interface, Botucatu, São Paulo, v. 16, n. 40, p. 205-218, jan./mar. 2012. Disponível em: http://www.scielo.br/pdf/icse/v16n40/aop1412.pdf. Acesso em: 14 nov. 2017.

SCHWENGBER, Maria Simone Vione. O uso das imagens como recurso metodológico. In: MEYER, Dagmar Estermann; PARAÍSO, Marluce Alves (org.). Metodologias de pesquisas pós-críticas em Educação. Belo Horizonte: Mazza Edições, 2014.

Submetido em: 10.12.2017

Aprovado em: 23.01.2019 